\title{
El concepto de violencia como motivo agonístico en Por qué perdimos la guerra (1940), de Diego Abad de Santillán. Análisis de un discurso anarquista en la inmediata posguerra
}

\author{
ROLF KAILUWEIT \\ Heinrich-Heine Universität Düsseldorf \\ orcid.org/0000-0002-8795-2121
}

Presentación: 12 feb. 2020 | Aceptación: 18 jun. 2020 | Publicación: 31 oct. 2020

Cita recomendada: Kailuweit, Rolf. 2020. «El concepto de violencia como motivo agonístico en Por qué perdimos la guerra (1940), de Diego Abad de Santillán. Análisis de un discurso anarquista en la inmediata posguerra». Dictatorships \& Democracies. Journal of History and Culture 8: 241-263. doi: https://dx.doi.org/10.7238/dd.voi8.3181

Resumen: En este artículo analizamos el concepto de violencia en Por qué perdimos la guerra, de Abad de Santillán, en el que explica la actuación anarquista durante la Guerra Civil. Basándonos en un enfoque de análisis del discurso foucaultiano, mostraremos que el texto actualiza los discursos legalista e ilegalista del siglo xIx. No obstante, estos reaparecen de forma modificada, puesto que los anarquistas ya no se oponen al poder estatal, sino que comparten este poder e incluso participan en el Gobierno. Nos centraremos en motivos agonísticos que representan posiciones opuestas sobre temas polémicos. La forma en que se expresan estas posiciones muestra si un discurso es históricamente hegemónico o no.

Palabras clave: violencia, poder, anarquismo, análisis del discurso, agonismo

The concept of violence as an agonistic motive in Por qué perdimos la guerra (1940), by Diego Abad de Santillán. Analysis of an anarchist discourse in the immediate postwar period

Abstract: In this paper we analyze the concept of violence in Abad de Santillán's Por qué perdimos la guerra, which explains the conduct of the anarchists during the Spanish Civil War. Basing our approach on the Foucauldian discourse analysis, we will show that the text updates the 19th century's legalist and illegalist discourse. However, these reappear modified, since the anarchists no longer oppose state power but share it and even participate in government. We focus on agonistic motives representing opposite positions on controversial issues. The way in which these positions are expressed shows whether a discourse is historically hegemonic or not.

Keywords: violence, power, anarchism, discourse analysis, agonism 
A Klaus Adomeit, in memoriam ${ }^{1}$

\section{Introducción}

El presente artículo se dedica al concepto de violencia y a su contextualización en el libro Por qué perdimos la guerra. Una contribución a la historia de la tragedia española, publicado en 1940 en el exilio argentino por el exlíder de la Federación Anarquista Ibérica (FAI) y ex consejero de Economía de la Generalitat de Cataluña, Diego Abad de Santillán. En el momento de la derrota se dirige a un público de sobrevivientes republicanos dispersos en el exilio o marginalizados en la clandestinidad durante los años de plomo de la dictadura franquista. En el libro resume los principios de la lucha anarquista desde el siglo XIX hasta el inicio de la Guerra Civil y justifica la actuación anarquista frente a la insurrección militar, a la Generalitat de Cataluña y a los partidos independentistas, así como frente al Gobierno central y a los partidos socialistas y comunistas.

Mostraremos que la obra de Abad de Santillán, al abordar el tema de la violencia y su justificación, actualiza los discursos legalista e ilegalista ya presentes en el siglo xIx. Sin embargo, estos discursos aparecen modificados, ya que las posturas anarquistas frente al poder (o frente a la lucha contra el poder) cambian en el momento en que los anarquistas defienden la República contra el fascismo e incluso participan en el Gobierno regional y en el central.

Aplicamos un método de análisis del discurso basado en los escritos de Michel Foucault. No obstante, hacemos hincapié en el hecho de que los discursos solo se construyen a través de la perspectiva subjetiva del intérprete en un proceso de contextualización hermenéutica. En nuestro

1 Dedico este artículo al profesor Klaus Adomeit (1932-2019), catedrático de derecho civil y laboral y filosofía del derecho en la Universidad Libre de Berlín y primer presidente de la Asociación Hispano-Alemana de Juristas. En 1990 me propuso un trabajo sobre el concepto de violencia en el anarquismo español del siglo Xıx, del que se publicó un resumen en la revista Tranvía ese mismo año (Kailuweit 1990). Ironías del destino, en 1996 el domicilio privado de Adomeit fue el objetivo de un atentado con bomba, cuyos autores, de extrema izquierda, criticaron sus posturas neoliberales en el campo del derecho laboral (Adomeit 1999). Solo hubo daños a la propiedad. 
análisis nos centraremos en motivos agonísticos, es decir, en temas en los cuales el texto revela tensiones discursivas acerca de la pretensión de validez de presunciones básicas. Mostraremos que, al presentar las posturas defendidas en el texto, las estrategias retóricas vacilan. Dado que el texto refleja en 1940 el triunfo revolucionario de julio de 1936 y las luchas internas que condujeron a la neutralización de los anarquistas y a la pérdida definitiva de la Guerra Civil en 1939, observamos que recurre tanto a estrategias propias del discurso dominante y hegemónico como a estrategias propias del discurso marginal o subversivo.

\section{Análisis de discurso: motivos agonísticos²}

En lo que sigue, nos basamos en la conceptualización del discurso que formula Michel Foucault en Las palabras y las cosas. ${ }^{3}$ Las formaciones discursivas constituyen recursos de conocimiento en el habla, que en cierta medida se interponen entre el nivel de la percepción y la práctica y el nivel de la reflexión científica teórica. Los discursos son «verdades» que no requieren ninguna justificación teórica para orientar la acción:

Así, entre la mirada ya codificada y el conocimiento reflexivo, existe una región media que entrega el orden en su ser mismo: es allí donde aparece, según las culturas y según las épocas, continuo y graduado o cortado y discontinuo, ligado al espacio o constituido en cada momento por el empuje del tiempo, manifiesto en una tabla de variantes o definido por sistemas separados de coherencias, compuesto de semejanzas que se siguen más y más cerca o se corresponden especularmente, organizado en torno a diferencias que se cruzan, etc. Tanto que esta región «media», en la medida en que manifiesta los modos de ser del orden, puede considerarse como la más fundamental: anterior a las palabras, a las percepciones y a los gestos [...]; más sólida, más arcaica, menos dudosa, siempre más «verdadera» que las teorías que intentan darle una forma explícita, una aplicación exhaustiva o un fundamento filosófico. Así, existe en toda

2 Este apartado desarrolla y modifica consideraciones teóricas que se abordan de manera análoga en Kailuweit (en prensa).

3 Citamos la traducción española de 1968. El original francés (Les mots et les choses) data de 1966. 
cultura, entre el uso de lo que pudiéramos llamar los códigos ordenadores y las reflexiones sobre orden, una experiencia desnuda del orden y sin modos de ser. (Foucault 1968, 6)

En nuestro campo de análisis, esta «región media» se manifiesta en declaraciones («enunciados» en el sentido de Foucault en La arqueología del saber $)^{4}$ sobre la violencia, la fuerza, el poder, etc., en diferentes géneros textuales. El discurso como región media se distingue de la práctica (la lucha anarquista) a la que sirve de orientación. Además, siendo más «verdadero», no necesita justificaciones basadas en teorías exhaustivas de fundamento filosófico (como las de Proudhon, Bakunin, Kropotkin, etc.).

El discurso consiste en «segmentos de conocimiento» (Busse 2019, 41) que se pueden encontrar en textos particulares, entendidos como productos de enunciaciones, y que se pueden asignar a diferentes tradiciones textuales. Según Foucault (2002,131-145), debe distinguirse la enunciación de los enunciados, que no están vinculados a una forma lingüística concreta. Aunque los enunciados pueden traducirse básicamente a diferentes idiomas y manifestarse en diferentes tipos de texto, la forma lingüística concreta no parece que sea irrelevante para su efecto discursivo. A este respecto, la elección del idioma, del tipo de texto y del estilo siempre deben reflejarse en la lingüística del discurso a la hora de determinar los efectos discursivos.

Contrariamente al pasaje citado de Las cosas y las palabras, que sugiere la existencia de capas de diferentes órdenes (lenguaje y percepción, conocimiento como discurso y reflexión teórica), en La arqueología del saber Foucault hace hincapié en que los discursos constituidos por signos son «prácticas que forman sistemáticamente los objetos de que hablan» (Foucault 2002, 81).

Partiendo de esta base, consideramos el discurso una práctica «plana» de enunciaciones encadenadas que no se basa en una estructura discursiva «profunda» que forma competencia lingüístico-cognitiva de los hablantes (Kailuweit en prensa). Al igual que Busse y Teubert (1994, 5), consideramos el análisis del discurso como una disciplina hermenéutica, ya

4 Citamos la edición argentina de 2002. El original francés (L'archéologie du savoir) data de 1969. DICTATORSHIPS \& DEMOCRACIES 8 (2020) · E-ISSN: 2564-8829 - PUNCTUM, UNIVERSITAT OBERTA DE CATALUNYA \& FUNDACIÓ CARLES PI I SUNYER 
que las relaciones discursivas no pueden existir como relaciones de significado independientemente de su interpretación. La constitución del discurso siempre presupone el proceso interpretativo de los investigadores. Sin embargo, el trabajo interpretativo no libera el significado de las manifestaciones discursivas, y mucho menos la intención del autor, sino que las coloca en un contexto (abierto) de cadenas discursivas.

Cabe señalar que la aplicación de métodos cuantitativos para analizar estas cadenas es de uso limitado, particularmente en el contexto histórico. Esto se debe tanto a la heterogeneidad de los tipos de texto como al carácter arbitrario de la tradición histórica. El análisis aquí presentado se basa en una aclaración del potencial discursivo de las formaciones textuales inmanentes en el libro de Diego Abad de Santillán Por qué perdimos la guerra sobre la base de una visión interpretativa subjetiva. Los aspectos cuantitativos, la cuantificación de ocurrencias y colocaciones, se incluyen en la interpretación, pero no son prevalentes. El análisis, pues, está basado en datos (data based), pero no determinado por los datos (data driven).

Recordemos que la verdad que Foucault atribuye a los discursos en Las palabras y las cosas no es objetiva, sino retórica. Se impone, según el «principio de la agonística» (Lyotard 2009, 40), no como mejor argumento en el diálogo, sino por el éxito de estrategias retóricas. Presentar sus presunciones básicas como verdades irrefutables indica la hegemonía retórica de un discurso, que puede darse el lujo de ignorar a los demás, a los contradiscursos. Los discursos no hegemónicos deben formular su pretensión de validez en contraste con los discursos hegemónicos. La oposición entre diferentes discursos, muy a menudo jerárquica, se manifiesta, según Felder $(2015,111)$, en «centros agonísticos». Estos centros pueden identificarse en los discursos como dicotomías abstractas de conceptos que guían la acción. Los discursos anarquistas del siglo xIX, por ejemplo, se organizan en torno a dicotomías como desigualdad-igualdad, esclavitud-libertad, injusticia-justicia, etc., que describen la sociedad (Kailuweit 1990, 74). La presentación de estas dicotomías deja entrever que hay discursos competitivos que luchan por imponer su visión de la realidad política y social. El término «centro» que propone Felder sugiere que se identifique un tema central, alrededor del cual gira la discusión. No obstante, no parece muy acertado referirse al agonismo comparándolo con un movimiento circu- 
lar. El tema o concepto controvertido parece ser más bien un motivo para desarrollar estrategias agonísticas. Por eso, prefiero hablar de «motivos agonísticos» en lugar de «centros agonísticos».

Cabe distinguir una contienda retórica, donde se oponen agonistas, de una contienda física entre antagonistas. En el agón no se pretende la eliminación física del adversario. Los protagonistas respetan ciertas reglas, entre las cuales destaca que el enfrentamiento tiene que ser retórico y no físico y que el destinatario del texto tiene que decidir sobre la validez de la argumentación. Esto no excluye que los agonistas recurran a la propaganda y a estrategias de manipulación retórica, cuyos límites pueden ser objeto de perpetua redefinición. No es necesariamente el mejor argumento, según un juicio objetivo, el que se impone, pero lo que se impone sigue siendo un argumento. El agón silenciado por la censura y la represión se convierte en antagonismo. ${ }^{5}$ Quien quiera silenciar al otro o incluso exterminarlo no es un adversario, sino un enemigo.

\section{Anarquismo y violencia}

El examen matizado de la reducción del anarquismo a la violencia terrorista tiene un papel importante en la investigación española historiográfica después de Franco. Debido a la gran cantidad de estudios que hay sobre el tema, el objetivo de esta sección no puede ser proporcionar una descripción detallada de esta investigación. ${ }^{6}$ Nos limitaremos a dar una breve descripción de la historia del anarquismo en España y del motivo de la violencia, que por falta de espacio tendrá que ser sumaria.

Fue Pierre-Joseph Proudhon $(2005,220)$ quien en su libro ¿Qué es la propiedad? (Qu'est ce que la propriété?) de 1840 definió la anarquía como «ausencia de señor, de soberano». Los anarquistas rechazan el poder (estatal) y la autoridad social impuesta por la fuerza sobre el individuo en nombre de la libertad y de la justicia social.

5 «El antagonismo es lucha entre enemigos, mientras que el agonismo es una lucha entre adversarios» (Mouffe 2003, 115).

6 Vadillo (2019) proporciona una orientación sobre el estado de la cuestión. 
Los orígenes del anarquismo en España se remontan al revolucionario italiano Giuseppe Fanelli, que por iniciativa de Mijaíl Bakunin viajó a España para reclutar miembros para la Asociación Internacional de Trabajadores o Primera Internacional (fundada en Londres en 1864). La Federación Regional Española de la Asociación Internacional de Trabajadores (FREAIT) fue fundada en 1870 en el Congreso de los Trabajadores de Barcelona (Esenwein 1989, 15-21) y representó tanto a corrientes marxistas como al anarquismo, que se expandió por España (López Estudillo 2002; Paniagua 2012, 67-98). Después del triunfo del golpe de Estado de enero de 1874, con el que terminó el Sexenio Democrático, la FRE-AIT desarrolló sus actividades en la clandestinidad. Durante este tiempo experimentó un proceso de radicalización que llevó a su disolución en 1881 (Esenwein 1989, 51-77; Paniagua 2012, 94-98). Ese mismo año, el gobierno dirigido por Práxedes Mateo Sagasta aprobó la Ley de asociaciones y legalizó las actividades de las organizaciones de trabajadores. Entonces se fundó una nueva organización jurídica, la Federación de Trabajadores de la Región Española (FTRE), en que se impuso la fracción de los anarcosindicalistas, que, rechazando la violencia como estrategia de lucha política, optó por planteamientos moderados y reformistas (Esenwein 1989, 80-82; Paniagua 2012, 99-106).

Durante los años ochenta se intensificó el cisma entre los moderados y los que abogaban por la llamada «propaganda por el hecho» (del francés propagande par le fait). Esta estrategia se había discutido en el movimiento anarquista internacional a partir de los años setanta del siglo XIX. Las acciones ejemplares deberían despertar a la sociedad, basándose en el supuesto de que el impacto de una acción genera más repercusiones que la mera palabra (Avilés 2009, 170). Con la proliferación de los atentados con bombas y los asesinatos, la expresión «propaganda por el hecho» se convirtió cada vez más en sinónimo de ataques violentos y terroristas. En la década de los ochenta, la justificación o el rechazo de la lucha armada se equiparaba también con la oposición entre, por una parte, el llamado «anarcocomunismo», inspirado por las teorías de Piotr Kropotkin, que dominaba en las zonas rurales, y, por otra, los anarquistas vinculados con el movimiento obrero de los sectores urbanos e industriales, que optaron por un sindicalismo moderado y eran más propensos a la organización colectivista (Paniagua 2012, 102-106). En 1882 se cometieron asesinatos en 
la comarca de Jerez atribuidos a una sociedad secreta anarquista llamada Mano Negra. Independientemente de si esta sociedad secreta realmente existió, es significativo que los asesinatos fueran rechazados por el sector moderado del anarquismo español (Avilés 2009, 172).

El escenario cambió en la década de 189o, cuando una serie de ataques y la posterior represión estatal desencadenaron una espiral de violencia y contraviolencia en Cataluña (Casanova 2005, 82). La propaganda de los hechos se complementó con la propaganda de la represión y del martirio. En particular, la detención de numerosas personas inocentes después del atentado con bomba en el Liceo en 1893, de quienes se obtuvieron falsas confesiones mediante torturas bestiales, llevó a solidarizarse con los mártires, incluso en los círculos anarquistas que habían condenado el uso de bombas (Avilés y Herreín 2010, 175-186).

La oposición fundamental entre la opción ilegalista y el sindicalismo moderado continuó en el siglo xx. La Confederación Nacional del Trabajo (CNT), fundada en 1910, optó por estrategias que permitieran actuar en la legalidad, aunque mantuvo una postura antipolítica y continuó rechazando al Estado y sus instituciones. Se convirtió en el sindicato español más importante durante las décadas posteriores. ${ }^{7}$ En su seno hubo también tendencias que rechazaban posturas reformistas, defendiendo el espíritu espontáneo revolucionario de las masas. En 1927, el crecimiento de este sector anarquista más radical condujo a la fundación de la Federación Anarquista Ibérica (FAI), que se definía como la vanguardia inspiradora del sindicato y abogaba por la coordinación orgánica entre la CNT y otras organizaciones anarquistas que no excluían la violencia como estrategia política (Bernecker 1978, 22; Paniagua 2012, 142-165).

\section{Las opciones discursivas anarquistas con respecto a la violencia}

En Kailuweit (1990), presenté los resultados de un trabajo académico de filosofía del derecho sobre el concepto de violencia en los discursos anar-

7 Según Casanova $(\mathbf{2 0 0 5}, 80)$, con la fundación y consolidación de la CNT como movimiento popular, España comenzó a ser atípica, porque por entonces el sindicalismo revolucionario, antipolítico y de acción directa había desaparecido del resto del mundo. 
quistas en el siglo xıx. Opté por un análisis del discurso foucaultiano, ya que el anarquismo español no ha generado una teoría cerrada de la lucha de clases. Los manifiestos, artículos, memorias y declaraciones de anarquistas españoles de la época tampoco son fragmentos a partir de los cuales se pueda reconstruir una teoría de esa naturaleza. Se sitúan más bien en la región «media» descrita por Foucault $(1968,6)$. Se trata de enunciados que manifiestan un orden en la conceptualización de la sociedad que no necesitan un fundamento teórico sofisticado. Operan con dicotomías sencillas, motivos agonísticos que se oponen, a través de la fuerza retórica, a la conceptualización dominante promulgada por las autoridades estatales y eclesiásticas.

Para analizar este discurso, me basé en un gran número de actas de congresos, panfletos, artículos de prensa y memorias de activistas, compilados por Clara E. Lida en sus libros de 1972 y 1973 Anarquismo y revolución en la España del XIX y Antecedentes y desarrollo del movimiento obrero español. Textos y documentos. También recurrí a la Contribución a la historia del movimiento obrero español (1962), de Diego Abad de Santillán, y a El proletario militante (1939), las memorias de Anselmo Lorenzo.

Llama la atención que los enunciados actualizados en estos textos muestren una gran uniformidad y a menudo sean idénticos en sus enunciaciones. Constituyen un discurso que opera básicamente entre los polos de la contingencia y la necesidad. Desarrollan una dicotomía entre la sociedad presente, contingente, y la que vendrá por necesidad histórica. La sociedad presente está caracterizada por atributos (rasgos) que obtienen valores negativos, a los que corresponden respectivamente atributos de valores positivos en la sociedad del porvenir.

Tabla 1. Dicotomías en el discurso anarquista del siglo XIX

\begin{tabular}{ll} 
Contingencia & Necesidad \\
\hline Sociedad presente & Sociedad del porvenir \\
\hline Leyes & Derechos/deberes \\
\hline Injusticia & Justicia \\
\hline
\end{tabular}




\begin{tabular}{ll} 
Contingencia & Necesidad \\
\hline Desigualdad & Igualdad \\
\hline Política & Administración \\
\hline Propiedad individual & Propiedad colectiva \\
\hline Guerra & Paz \\
\hline Esclavitud & Libertad \\
\hline Mentira & Verdad \\
\hline Corrupción & Moralidad
\end{tabular}

La injusticia de la sociedad presente es contingente, ya que no tiene justificación religiosa o secular. Las leyes vigentes son una expresión de la arbitrariedad de los que están en el poder. Son incompatibles con los derechos naturales, que inevitablemente se impondrán en la sociedad futura. No obstante, los derechos también corresponden a los deberes, especialmente al deber de trabajar, que la clase dominante evade. La sociedad en la que todos los que trabajen puedan disfrutar de sus derechos será igualitaria y justa. Será una sociedad donde reine la libertad, la verdad y la moralidad, en contraste con la sociedad presente, caracterizada por la corrupción, la mentira y la esclavitud de los trabajadores.

La transición de la sociedad presente a la del porvenir se conseguirá por medio de la lucha y la revolución. Sin embargo, no se indica si la lucha y la revolución están vinculadas al uso de la violencia o no. La cuestión se resuelve de manera diferente dependiendo de si los locutores argumentan desde la posición de legalidad o de ilegalidad. Podemos distinguir, así pues, dos subdiscursos: uno ilegalista y otro legalista. ${ }^{8}$

8 La oposición entre ilegalismo y legalismo se encuentra sobre todo en la historiografía francesa del movimiento obrero (Maitron 1975, 409-ss.; Chambost 2017). Si bien el término «ilegalismo» también se usa en la historiografía española (López Estudillo 2009; Marin 2014, 139-ss.), un discurso que aboga por actuar dentro del marco de la legalidad se define comúnmente con el adjetivo «moderado». Con los términos «ilegalismo» $\mathrm{y}$ «legalismo» nos referimos a formaciones discursivas que actualizan diferentes sujetos de la enunciación en diferentes momentos. No es una atribución ideológica que debería servir para caracterizar a individuos o grupos de personas. Esto quedará claro en el análisis de Por qué perdimos la guerra, que contiene enunciados que actualizan uno u otro discurso. No su- 
Para el discurso ilegalista, el enemigo de clase es un parásito y un asesino. Con él no se comparte ningún sistema legal. Los que no están unidos por el derecho están en estado de guerra. La guerra solo puede terminar por la fuerza. La violencia es necesaria y no constituye una respuesta contingente a medidas arbitrarias. Es legítima porque sirve para luchar contra el enemigo y construir una sociedad justa. Cualquiera que acepte el sistema legal existente no es un anarquista, sino un ilusionista, un reaccionario o un cómplice del sistema vigente.

Para el discurso legalista la violencia, como hecho contingente, es ultima ratio en momentos de extrema represión. Los derechos naturales tienen vigencia eterna. Por eso, se aplican tanto a la sociedad presente como a la del porvenir. Los actos de violencia son crímenes. Los autores de atentados son nihilistas y locos que invocan erróneamente el anarquismo. La lucha es pacífica y se lleva a cabo con las armas de la razón. La revolución tiene lugar en las mentes a través de la educación y la iluminación.

A continuación veremos cómo los discursos ilegalista y legalista reaparecen en Por qué perdimos la guerra. ${ }^{9}$

\section{Autor y obra}

Diego Abad de Santillán, protagonista clave del movimiento anarcosindicalista español, nació en 1897 en Reyero, en la provincia de León, y murió en 1983 en Barcelona. Se llamaba, en realidad, Sinesio Baudilio García Fernández. En 1905 emigró con sus padres a Argentina y regresó a España en 1912 para cursar el bachillerato. Entre 1915 y 1917 estudió filosofía y letras en Madrid, donde entró en contacto con los círculos anarquistas. Fue

ponemos que el texto permita reconstruir una posición ideológica coherente del autor y, en ausencia de esta, no vemos ninguna razón para criticarlo. En este sentido, el nuestro difiere de enfoques historiográficos menos fundamentados en el análisis del discurso.

9 En la presente contribución, nos limitamos a un análisis de este libro de Abad de Santillán, y no solo por razones de espacio. No es nuestro objetivo reconstruir los cambios en el posicionamiento ideológico del autor analizando toda su obra, sino más bien mostrar cómo se actualizan y modifican discursos históricos sobre la violencia en Por qué perdimos la guerra, que se publicó en el período inmediatamente posterior a la Guerra Civil. Es de esta manera como quisimos contribuir al tema del simposio ¿Ha terminado la Guerra Civil? España 1939-1953 (Düsseldorf, 18 y 19 de octubre de 2019), en el que presentamos las ideas principales de nuestro enfoque. 
condenado a un año y medio de cárcel por su participación en la huelga general de 1917. Puesto en libertad, se exilió a Argentina en 1918, donde militó en la Federación Obrera Regional Argentina (FORA), a la que representó en 1922 en Berlín en el congreso fundacional de la Asociación Internacional de los Trabajadores (AIT). Entre 1922 y 1926 cursó estudios de medicina en Berlín, donde conoció a su futura esposa, Elise Kater, hija del anarquista Fritz Kater. En años posteriores, vivió entre México, Argentina, Uruguay y España. En 1933 se instaló en Barcelona y dos años después fue secretario del Comité Peninsular de la FAI. Después de la victoria de las fuerzas libertarias en julio de 1936, entre diciembre de ese año y abril de 1937, fue consejero de Economía de la Generalitat de Cataluña. En el momento de la derrota, se exilió a Argentina. Regresó a Barcelona en 1977, donde vivió hasta su muerte (Elorza 1976, 9-12; Fernando de la Rosa 2012, 24-27; Migueláñez Martínez 2013).

Abad de Santillán es autor de varios libros de teoría económica del anarquismo y de historia del movimiento obrero en España, Argentina y México. Publicó Por qué perdimos la guerra en Buenos Aires en la inmediata posguerra, en 1940. En 2018, la obra fue reeditada por la editorial Almuzara de Córdoba (España). Hemos trabajado con la versión en PDF de la primera edición argentina. ${ }^{10}$ Esta versión constituye un corpus de 120.268 palabras. Hemos utilizado el programa AntConc, versión 3.5.7 (2018), para los análisis cuantitativos.

\section{El concepto de violencia en Por qué perdimos la guerra, de Abad de Santillán}

El libro de Abad de Santillán es de especial interés en cuanto al concepto de violencia en el discurso anarquista, porque actualiza enunciados que se refieren al uso de la fuerza no solo desde abajo, es decir, desde la perspectiva del movimiento obrero reprimido en contra de las autoridades estatales, sino también desde arriba, desde el punto de vista de los anarquistas victoriosos en el poder.

10 Disponible en http://www.fondation-besnard.org/spip.php?article882. 
El término «violencia» y sus derivaciones no son frecuentes en la obra. Contamos solo 17 ocurrencias para la búsqueda de «[violen*]». La búsqueda de «[luch*]», incluyendo el substantivo «lucha» y las formas del verbo «luchar», obtiene 169 resultados, de los cuales 105 corresponden a la forma nominal. Casi siempre se refiere a la lucha armada, es decir, al uso de la violencia. Las colocaciones son muy heterogéneas. Aparecen «lucha sangrienta» (tres ocurrencias), «lucha armada» (dos ocurrencias), «lucha intestina» (dos ocurrencias) y «lucha violenta» (una ocurrencia).

Los substantivos más frecuentes son «guerra» (568 ocurrencias), «gobierno» (366 ocurrencias), «España» (311 ocurrencias) y «pueblo» (234 ocurrencias). Por medio de estos nombres, se puede resumir el tema general de la obra, aunque «guerra» $\mathrm{y}$ "gobierno» no tengan un referente único a causa de los abundantes excursos históricos que hay en el libro. En líneas generales, Por qué perdimos la guerra trata sobre la guerra contra la sublevación militar, a la que los anarquistas, como representantes del pueblo, se opusieron, mientras que el papel del Gobierno (central y regional) queda en posición dudosa:

Los gobiernos, los despotismos, las tiranías, los regímenes políticos de privilegio pasan, pero un pueblo como el nuestro, que no ha desaparecido ya, es de una vitalidad única que le ha hecho persistir contra los embates de los que porfiaron en todos los tiempos por desviar el sentido y la dirección de su historia [...]. Si la sublevación militar de los generales ha desembocado en una gran guerra, se debe todo ello a nuestra intervención combativa. No fue la República la que supo y la que fue capaz de defenderse contra la agresión; fuimos nosotros los que, en defensa del pueblo, hemos hecho posible el mantenimiento de la República y la organización de la guerra. (Abad de Santillán 1940, 3 y s.)

Después del fracaso de los intentos revolucionarios faístas de 1932 y 1933, Abad de Santillán se centró en cuestiones económicas y se mostró más abierto a la colaboración estratégica con otras fuerzas de la izquierda (Elorza 1976; Migueláñez Martínez 2013). Sin referirse a posturas personales, en Por qué perdimos la guerra el sujeto del enunciado describe este proceso como un cambio de rumbo en que estaba implicada la gran mayoría de los militantes anarquistas. Describe el enfrentamiento violento 
con las instituciones republicanas, que caracterizó la posición cenetista en 1933, con una construcción elusiva de pasiva refleja (a la que añade, no obstante, un complemento agente): «Una violenta campaña antielectoral se desarrolló en todo el país, por parte de nuestras organizaciones» (Abad de Santillán 1940, 21). Pasa después a la construcción activa con la mención del agente colectivo «nosotros», en el que se incluye:

Evitamos la repetición de la campaña antielectoral de noviembre de 1933 [...] sin otro objetivo que el de contribuir, de este modo, a desalojar del Gobierno a las fuerzas políticas de la reacción fascista y el de libertar a los presos [...]. Sin la victoria electoral del 16 de febrero no hubiéramos tenido el 19 de julio. (Abad de Santillán, 24)

Deja entrever al final un motivo agonístico al referirse, de forma hegemónica, a aquellos que mantuvieron una postura antipolítica: «Los esfuerzos de algunos pseudo-puritanos para contrarrestar nuestra manera de ver, fueron frustrados fácilmente» (Abad de Santillán, 24).

\subsection{La justificación de la violencia}

Sin embargo, para justificar la oposición violenta al fascismo, el texto recurre a motivos conocidos del discurso ilegalista. Es la «justicia» que se enfrenta con «los poderes de las tinieblas y de la esclavitud»: «Lo más florido, lo más generoso e inteligente de un pueblo moría con la sonrisa en los labios, desafiando a los poderes de las tinieblas y de la esclavitud, puesta la esperanza en el triunfo de la justicia» (Abad de Santillán, 2). «Pueblo» resulta otra vez el concepto clave del discurso. El pueblo aparece como unidad indivisible, como se ve con mayor claridad en el siguiente fragmento referido a los acontecimientos barceloneses de julio de 1936: «No había partidos, no había organizaciones, aun cuando se circulaba bajo la insignia roja y negra de los vencedores. ¡Había solamente un pueblo en la calle! Un pueblo con un solo pensamiento, con una sola voluntad, con un solo brazo» (Abad de Santillán, 34). El pueblo y las masas trabajadoras y campesinas no están dividas en defensores y en opositores del fascismo. 
Debe observarse que la instancia de la cual habla el sujeto del enunciado, el «nosotros» (257 ocurrencias), ${ }^{11}$ no es idéntica a la de «pueblo», pero sí está estrechamente conectada con él: «Teníamos un arma de que el Gobierno central carecía: la adhesión activa del pueblo» (Abad de Santillán, 74); «Teníamos la seguridad de ser los únicos que aún podríamos galvanizar la voluntad de las masas trabajadoras y campesinas, tanto por la cantidad como por la calidad de nuestros militantes» (Abad de Santillán, 224).

El concepto de pueblo implica además que la guerra no se considere civil. El término «guerra civil» solo se menciona siete veces en la obra, de las cuales solo cinco se refieren a los años entre 1936 y 1939. Solo una vez aparece el término «ciudadano», y eso solo al inicio de la obra. El hecho de que el texto apele al ciudadano como instancia neutra, que es el objetivo de los discursos agonísticos, contrasta con el concepto de pueblo al que se adhieren las ideas del movimiento anarquista:

Es casi un deber, después de todos los horrores que se han divulgado sobre la actuación de los hombres de la Federación Anarquista Ibérica, antes y después de julio de 1936, para todo ciudadano del término medio, atribuirnos todos los defectos y echarnos a la espalda todas las maldades [...]. ¿No se ha de permitir ahora, cuando estamos vencidos, que alguien que ha tenido en esa organización revolucionaria los más altos cargos [...] levante un poco el telón y diga la verdad? (Abad de Santillán, 3)

Cabe señalar que el agonista que «divulga horrores» sobre la actuación de los anarquistas no es partidario del franquismo - este es el enemigo-, sino que representa al partido republicano y a las fuerza socialistas y comunistas que estuvieron en el Gobierno entre 1936 y 1939. El hecho de que el sujeto del enunciado subraye que toma la palabra para rectificar las mentiras difundidas por otros indica que su posición discursiva no es la dominante. Son los que «divulgan horrores» quienes dominan el discurso, y la falsedad de su retórica la que hace que sea necesario tomar posición.

11 La referencia de este «nosotros» resulta vaga. Podemos suponer que denota en su extensión más amplia a la CNT, que contaba en 1936 con 550.000 afiliados, y a la FAI, con 30.000 militantes. 
No obstante, como veremos más en detalle a continuación, la relación entre el movimiento anarquista y el poder republicano durante la guerra no es de plena oposición, sino que resulta más ambigua. En aparente contradicción con los principios del anarquismo, los anarquistas formaron parte del Gobierno y respetaron cada vez más el sistema legal sobre el cual se fundaba la República. Eso ya comenzó con la renuncia a la abstención electoral en febrero de 1936.

En este contexto, llama la atención que el texto justifique también la lucha antifascista en términos puramente legalistas. En el siguiente fragmento, recurrir a la violencia contra los rebeldes militares franquistas no se justifica porque representaban «los poderes de las tinieblas y de la esclavitud», sino porque habían violado las leyes republicanas en un acto de alta traición:

No negamos a nadie el derecho a la rebelión contra lo que se juzga inapropiado para asegurar una convivencia más justiciera y más digna. Nosotros mismos nos hemos rebelado contra la República en varias ocasiones, y desde antes de su proclamación habíamos manifestado nuestra entera independencia, sabiendo por anticipado que no sabría ni podría dar solución a los eternos problemas del país. Pero los militares no estaban, sin embargo, en nuestro caso. Nosotros no habíamos jurado ni empeñado nuestra palabra de honor, ni adquirido ningún compromiso de fidelidad al régimen republicano. Los militares que se rebelaron habían jurado esa fidelidad, estaban en cargos de la máxima responsabilidad a sueldo de la República. La conspiración tenía su primer peldaño en la traición a los propios compromisos [...]. (Abad de Santillán, 24)

En esta línea, argumenta que ya no son los anarquistas quienes recurren a la violencia, justificada en la tradición del discurso ilegalista. El texto enfatiza que es el pueblo el que usa la violencia sin ser incitado por los militantes de la CNT o la FAI. Los argumentos del discurso ilegalista reaparecen para hacer comprensible estas acciones y se introducen aquí de una manera retóricamente sofisticada a través de una cita del autor romántico Mariano José de Larra, que se refiere, como es natural, a otro contexto histórico, la quema de conventos en 1836 : 
No hemos impedido que las iglesias y conventos fuesen atacados como represalia por la resistencia hecha desde ellos por el ejército y los siervos de Dios. [...] El pueblo, por propia iniciativa, tomó sus venganzas bien comprensibles [...] Ni la C. N. T. ni la F. A. I. dieron aliento a esa acción estéril, de mera revancha. Lo decimos porque esta es la verdad, y si no hubiésemos procedido así, tampoco habría sido un delito como para arrepentirnos. Recordamos unas palabras de Mariano de Larra [...] refiriéndose precisamente a excesos populares semejantes: «Tales escenas de incendio y carnicería podrán ser terribles, pero su explicación es justa y sencilla [...] esas escenas mortíferas no son, como se quiere suponer, efectos de feroces caprichos y de un instinto ciego y desordenado, sino la consecuencia llevada al extremo solamente del derecho de defensa que tiene toda sociedad al verse acometida [...]». (Abad de Santillán, 36)

Si bien aquí se muestra una posición de observación neutral, en el siguiente fragmento la instancia «nosotros» se convierte en un agente que suprime el uso de la violencia si la considera excesiva. Representa su ejecución como un medio justo de castigo, aunque los responsables de los «excesos» fueran «compañeros y amigos». Es curioso leer que el sujeto del enunciado, en nombre de los anarquistas, defienda el monopolio estatal de la violencia cuando los anarquistas se hicieron cargo de las fuerzas del orden en los meses que siguieron a la victoria de julio de 1936: «Hicimos advertencias serias con vistas a reprimir todo exceso, y por si llegaba a creerse que esas advertencias no alcanzaban a todos, fusilamos a algunos compañeros y amigos nuestros que se habían extralimitado» (Abad de Santillán, 42).

La ambigua relación con el poder se muestra también en la descripción de los acontecimientos en Cataluña después de la victoria en julio de 1936. El sujeto del enunciado justifica mediante el ideario anarquista el hecho de que las fuerzas libertarias dejaran a la Generalidad al frente del poder y esta lo compartiera con representantes anarquistas y de los partidos socialistas y comunistas: "Nosotros no creíamos en la dictadura cuando se ejercía contra nosotros y no la deseábamos cuando la podíamos ejercer nosotros en daño de los demás» (Abad de Santillán, 35).

Este compromiso lleva a una cadena de acciones de retaguardia a partir de 1937. No es este el lugar para seguir de cerca el enfrentamiento re- 
tórico con el comunismo, con los agentes rusos y con sus representantes en el Gobierno central antes y sobre todo después de que Juan Negrín tomara el poder en mayo de 1937. En el apartado siguiente solo nos concentramos en la manera de justificar que los anarquistas renunciaran a oponerse violentamente al Gobierno republicano. Veremos que, a causa de la guerra, en el texto aparecen argumentos diferentes de los que caracterizaron el discurso legalista en el siglo xIX.

\subsection{La justificación de no rebelarse ante la contrarrevolución}

El primer argumento aducido para no rebelarse contra la llamada «contrarrevolución republicana» es que tal rebelión habría dañado la lucha antifascista. El sujeto del enunciado explica la aceptación de la disolución del Comité Central de las Milicias Antifascistas de Cataluña en octubre de 1936, por la cual los anarquistas perdieron gran parte de su influencia en la organización estatal. Sostiene que, «no teniendo otro dilema que ceder o empeorar las condiciones de la contienda, puesto que tampoco se quería recurrir a procedimientos de fuerza para obtener lo que nos correspondía, nosotros, que teníamos más razón, hubimos de ceder» (Abad de Santillán, 83).

En mayo de 1937 estalló un conflicto violento en Barcelona: «Luchaban fuerzas libertarias populares contra los comunistas y sus aliados» (Abad de Santillán, 97). El enfrentamiento terminó con la retirada de los anarquistas. En retrospectiva, el sujeto del enunciado califica la renuncia a la violencia como un error táctico: «Nos acusamos de haber sido causa principal de la suspensión de la lucha. No con orgullo, sino con arrepentimiento» (Abad de Santillán, 98). El fragmento siguiente explica que la instancia «nosotros», los representantes de la CNT y la FAI en Cataluña, temía «la pérdida total de la autonomía catalana y de la pérdida de la guerra como consecuencia», por lo cual «era hora todavía de oponerse a ese desenlace y de dejar a las cosas mejor situadas» (Abad de Santillán, 100). El sujeto del enunciado deja entrever que esta decisión se motivó en primer lugar por la desunión entre los líderes anarquistas en Cataluña y los representantes de la CNT en Madrid: «No nos faltaba la fuerza material [...] nos faltaba confianza en los que se habían erigido en representantes DICTATORSHIPS \& DEMOCRACIES 8 (2020) - E-ISSN: 2564-8829 - PUNCTUM, UNIVERSITAT OBERTA DE CATALUNYA \& FUNDACIÓ CARLES PII SUNYER 
de nuestro movimiento» (Abad de Santillán, 10o). A pesar de sus críticas iniciales, la CNT decidió volver a participar en el Gobierno republicano dirigido por Negrín. En el texto se comenta de la manera siguiente:

Se había caracterizado al Gobierno Negrín en mayo de 1937, en común acuerdo con todo el movimiento libertario, como «gobierno de la contrarrevolución». Unos meses más tarde, cuando la contrarrevolución no era una tendencia sino un hecho generalizado, solo muy pocos quedábamos fieles a las propias convicciones [...] nuestras queridas organizaciones compitiendo en celo gubernativo con los demás partidos y organizaciones, consintiendo voluntariamente en servir de meros instrumentos pasivos a disposición del Dr. Negrín. (Abad de Santillán, 156)

En resumen, el sujeto del enunciado lamenta la lealtad de los anarquistas con respecto al Gobierno republicano: «El mayor error de que se nos acusará ha de ser el de haber sido leales y sinceros en toda nuestra actuación pública, incluso mientras se afilaba en las sombras el puñal de la traición de los que se sentaban a nuestro lado» (Abad de Santillán, 54). Dado que, en principio, los anarquistas no respetaron las leyes de la República, es curioso que el sujeto del enunciado represente la lealtad y sinceridad en la actuación política como valores morales y no solo como una posición táctica para no perder la guerra. Tal vez la ambigüedad retórica se explica por el hecho de que el texto se dirige a un público de extranjeros $\mathrm{y}$ «ciudadanos del término medio» que se oponen al fascismo identificándose con la República Española en general, sin opinar en detalle sobre la justicia de su organización política y económica.

\section{7 ¿Ha terminado la Guerra Civil?}

Por qué perdimos la guerra no solo analiza los acontecimientos entre 1936 y 1939 para determinar las razones de la derrota y explicar y justificar la actuación anarquista. También abunda en consideraciones históricas y especulativas que pueden considerarse perspectivas lúcidas sobre las razones de los conflictos violentos que sufre España, tanto en el pasado como en el presente siglo XXI. 
Aparece varias veces el tópico de las dos Españas, pero de una manera inusual y original. La historiografía generalmente establece un contraste entre, por un lado, un entorno urbano progresista, anticlerical, liberal, republicano y democrático, y, por otro, un entorno rural conservador, católico, tradicionalista, autoritarista y monárquico (Juliá 2004). En cambio, el sujeto del enunciado avanza la tesis de que las dos Españas no corresponden a esta oposición. Hace hincapié en que «esas dos Españas no se identifican por los términos corrientes y en boga de izquierdas y derechas, liberales y conservadores; muy a menudo vemos en unas y en otras las mismas contradicciones, la misma repulsión interna» (Abad de Santillán 1940, 9). El sujeto del enunciado pone en contraste «dos herencias que luchan por sobrevivir en nuestro suelo: Europa y África» (Abad de Santillán, 10) y considera los verdaderos destinos de España «más ligados a lo africano que a lo europeo» (Abad de Santillán, 10). La Iglesia católica romana, así como las dinastías de los Austrias y de los Borbones, se encuentran entre las influencias europeas que introdujeron el centralismo en España. En el contexto de la inmediata posguerra, se consideran europeístas tanto al franquismo, dependiente del fascismo alemán e italiano, como a los (ex) representantes de la República que se fiaban o bien de la Unión Soviética comunista, o bien de los gobiernos democráticos de Francia y Gran Bretaña. La España más tradicionalista, es decir, la que forma parte de un espacio cultural «africano», está representada por la defensa de los fueros por parte de las regiones e incluso por el carlismo del siglo XIX.

El término «tradición» aparece aquí como motivo agonístico. Con un gesto de deconstrucción — a la manera derridiana (véase Derrida 1977)—, el sujeto del enunciado se opone a los que pretenden representar el tradicionalismo en España y deconstruye la dicotomía entre una derecha tradicionalista y una izquierda progresista, atribuyendo al movimiento anarquista ser el verdadero representante de la tradición íbero-africana:

Se llaman tradicionalistas justamente los que menos se apoyan en la tradición española, los partidarios de las monarquías importadas, Austrias o Borbones, los partidarios del catolicismo romano [...]. Si hay tradicionalistas en España, los que van a la cabeza de la tradición somos nosotros, que no vemos para nuestros viejos problemas más que soluciones españolas, tan lejos del comu- 
nismo ruso, como del fascismo ítalo-germánico o del fofo liberalismo francés. (Abad de Santillán, 10 y s.)

El texto llega incluso a decir que los anarquistas están más cerca de algunos de sus adversarios conservadores de la derecha, y en particular, por ejemplo, de Primo de Riviera, que de las fuerzas europeístas de la izquierda: «Fue un error de parte de la República el fusilamiento de José Antonio Primo de Rivera; españoles de esa talla, patriotas como él no son peligrosos, ni siquiera en las filas enemigas. Pertenecen a los que reivindican a España y sostienen lo español aun desde campos opuestos» (Abad de Santillán, 12).

A pesar de esta postura atrevida, Por qué perdimos la guerra sigue siendo instructivo cuando trata de los conflictos que desgarran a España en estos días. Pone de relieve que es la desigualdad económica la que sigue motivando muchos de los profundos conflictos actuales y contribuye al debate sobre la memoria con su minuciosa descripción de los acontecimientos de la Guerra Civil.

No obstante, a mi parecer, la contribución más ingeniosa se refiere al federalismo, puesto que el centralismo se identifica como una de las principales causas que llevaron a la derrota de la Segunda República. Según el sujeto del enunciado, «la conducta del Gobierno de Madrid» está caracterizada por la «hostilidad no disimulada a todo lo procedente de Cataluña» (Abad de Santillán, 73). Constata que la Segunda República «había sido forzada a dar una apariencia de autonomía a Cataluña y a Euzkadi» (Abad de Santillán, 74). Sin embargo, «siguió apegada a la tradición centralista de la historia antiespañola» (Abad de Santillán, 74). Precisamente por eso, no aboga por la independencia de Cataluña. Deconstruye la oposición entre un españolismo de unidad y un federalismo que conduce a la desintegración. Al contrario, según el autor, «la solución política más acertada y la más eficaz habría estado en una España federal, en la que cada región tuviese la más completa autonomía para expresar libremente su sentido de la solidaridad nacional». Lamenta que «esa idea no ha[ya] prosperado, o no fue[ra] comprendida» (Abad de Santillán, 82). Ojalá que se entienda ahora para evitar más violencia. 


\section{Bibliografia}

Abad de Santillán, Diego. 1940. Por qué perdimos la guerra Una contribución a la historia de la tragedia española. Buenos Aires: Imán.

-1962. Contribución a la historia del movimiento obrero español. Puebla, México: Cajica.

- 2018. Por qué perdimos la guerra. Una contribución a la historia de la tragedia española. Córdoba: Almuzara.

Adomeit, Klaus. 1999. «Arbeitsrecht explosiv». En Walther Hadding, ed., Festgabe Zivilrechtslehrer 1934/35, 1-11. Berlín / Nueva York: De Gruyter.

Avilés, Juan. 2009. «El terrorismo anarquista como propaganda por el hecho: de la formulación teórica a los atentados de París, 1877-1894 (1)». Historia y Política 21: 169-19o.

Avilés, Juan, y Herrerín, Ángel. 2010. «Propaganda por el hecho y propaganda por la represión: anarquismo y violencia en España a fines del siglo XIX». Ayer 80: 165-192.

Bernecker, Walther L. 1978. Anarchismus und Bürgerkrieg. Zur Geschichte der sozialen Revolution in Spanien. Hamburgo: Hoffmann und Campe.

Busse, Dietrich. 2019. «Theoretische Grundlagen und methodische Aspekte einer vergleichenden Diskurslinguistik». En Goranka Rocco y Elmar Schafroth, ed., Vergleichende Diskurslinguistik. Methoden und Forschungspraxis, 37-57. Berlín: Peter Lang.

Casanova, Julián. 2005. «Terror and Violence: The Dark Face of Spanish Anarchism». International Labor and Working-Class History 67: 79-99.

Derrida, Jacques. 1977. «Posiciones. Entrevista con Jean-Louis Houdebine y Guy Scarpetta», traducción de M. Arranz. En Jacques Derrida, Posiciones, 51-131. Valencia: Pre-Textos.

Elorza, Antonio. 1976. «Diego Abad de Santillán: anarquismo y utopía». En Diego Abad de Santillán, El anarquismo y la revolución en España. Escritos 1930-38, 9-52. Madrid: Ayuso.

Esenwein, George R. 1989. Anarchist Ideology and the Working-Class Movement in Spain, 1868-1898. Berkeley / Los Angeles / Oxford: University of California Press.

Felder, Ekkehard. 2015. «Lexik und Grammatik der Agonalität in der linguistischen Diskursanalyse». En Heidrun Kämper y Ingo Warnke, ed., Diskurs - interdisziplinär. Zugänge, Gegenstände, Perspektiven, 87-121. Berlín/Boston: De Gruyter.

Foucault, Michel. 1968. Las palabras y las cosas. Una arqueología de las ciencias humanas. Ciudad de México: Siglo XXI Editores.

- 2002. La arqueología del saber. Buenos Aires: Siglo XXI.

Juliá Díaz, Santos. 2004. Historia de las dos Españas. Madrid: Taurus.

Kailuweit, Rolf. 1990. «Gewalt der Sprache - Der Diskurs der spanischen Anarchisten im 19. Jahrhundert». Tranvía 17: 73-76.

—. En prensa. «Agonale Diskurse: Zur Konstruktion von Katalanität im 18. und 19. Jahrhundert». En Sandra Issel-Dombert y Vicente Álvarez Vives, ed., Sprache - 
Raum - Konflikt. Sprachwissenschaftliche Perspektiven auf die Katalonienkrise, [Suplemento de PhiN (Philologie im Netz).

Lida, Clara E. 1972. Anarquismo y revolución en la España del XIX. Madrid: Siglo XXI de España.

- 1973. Antecedentes y desarrollo del movimiento obrero español. Textos y documentos, estudio y compilación. Madrid: Siglo XXI de España.

Lorenzo, Anselmo. 1939. El proletario militante. Toulouse: MLE-CNT en Francia.

Lyotard, Jean-François. 2009. La diferencia. Madrid: Gedisa.

Maitron, Jean. 1975. Le mouvement anarchiste en France. (Tome 1 - Des origines à 1914). París: Gallimard.

Marín, Dolors. 2014. Anarquismo. Una introducción. Barcelona: Ariel.

Migueláñez Martínez, María. 2013. «Diego Abad de Santillán (1897-1983): los viajes doctrinarios de un anarquista transnacional». En Manuel Pérez Ledesma, ed., Trayectorias trasatlánticas (Siglo XX). Personajes y redes entre España y América, 163198. Madrid: Polifemo.

Mouffe, Chantal. 2003. La paradoja democrática. Barcelona: Gedisa.

Paniagua, Javier. 2012. Breve historia del anarquismo. Madrid: Nowtilus.

Proudhon, Pierre-Joseph. 2005. ¿Qué es la propiedad? Investigaciones sobre el principio del derecho y del gobierno. Buenos Aires: Libros de Anarres.

Rosa, María Fernanda de la. 2012. «La figura de Diego Abad de Santillán como nexo entre el anarquismo argentino europeo y latinoamericano, 1920-1930». Iberoamericana 12 (48): 22-40.

Vadillo Muñoz, Julián. 2019. «El anarquismo español con, por y ante la Segunda República Española (1931-1936)». Cultura de la República. Revista de Análisis Crítico 3: $145-164$. 
